\title{
ANALISIS PENDAPATAN DAN KELAYAKAN USAHATANI TIMUN SURI DI GAMPONG BABAH JURONG KECAMATAN KUTA BARO KABUPATEN ACEH BESAR
}

\author{
Analysis Of The Income And Eligibility Of Farming Suri Cucumber In Gampong Babah \\ Jurong Kuta Baro Aceh Besar District
}

\author{
Febrina Ramadhani, Fajri, Zakiah* \\ ${ }^{1}$ Program Studi Agribisnis, Fakultas Pertanian, Universitas Syiah Kuala
}

\begin{abstract}
Abstrak. Usahatani timun suri. Tujuan penelitian ini adalah menganalisis keuntungan usahatani timun suri dan menganalisis kelayakan usahatani timun suri. Lokasi penelitian di lakukan di Gampong Babah Jurong Kecamatan Kuta Baro Kabupaten Aceh Besar, penelitian dilakukan pada bulan Mei-Juni tahun 2017. Metode penelitian yang digunakan adalah metode sensus yaitu seluruh populasi menjadi sampel. Metode pengumpulan data dilakukan dengan melakukan wawancara, observasi dan kuesioner dengan analisis kuantitatif. Hasil penelitian menunjukkan pendapatan yang diterima usahatani timun suri dengan luas lahan sebesar $750 \mathrm{~m}^{2}$ adalah $\mathrm{Rp} 1.501 .736$. Nilai R/C >1 yaitu sebesar 1,90 yang artinya usahatani timun suri dinilai layak untuk diusahakan. Nilai BEP produksi sebesar 467 dan BEP Harga sebesar 1.933, dimana titik pulang pokok usahatani timun suri terjadi pada saat produksi mencapai $467 \mathrm{~kg}$ dan harga minimun sebesar Rp 1.933/kg. Nilai ROI sebesar 90,19\%, yang artinya setiap Rp 100 biaya produksi yang dikeluarkan mampu memberikan pendapatan pada usahatani timun suri sebesar Rp 90,19. Dengan demikian, usahatani timun suri di Gampong Babah Jurong Kecamatan Kuta Baro Kabupaten Aceh Besar layak untuk diusahakan dan dapat memberikan keuntungan.
\end{abstract}

Kata kunci: Usahatani, Pendapatan, Kelayakan Usaha

Abstract. Farming cucumber suri. The purpose of this research is to analyze the benefits of farming cucumber suri and analyze the feasibility of farming timun suri. The location of the research done in Gampong Babah Jurong Kuta Baro, Aceh Besar Regency research conducted in May-June of 2017. The research method used was the census method, namely the population being sampled. Method of data collection is done by conducting interviews, observation and questionnaires with quantitative analysis. The results showed revenue received farming land with an area of suri cucumber of $750 \mathrm{~m}^{2}$ is $\mathrm{Rp} 1,501,736$. The value of $\mathrm{R} / \mathrm{C}>1$ i.e. of 1.90 , meaning farming cucumber suri is judged worthy to remain unanswered. The value of BEP production is 467 and BEP price is 1,933, where point staple farming cucumber suri occurs when the production reaches $467 \mathrm{~kg}$ and a minimum price of $\mathrm{Rp}$ $1.933 / \mathrm{kg}$. The value of ROI of $90.19 \%$, meaning that every Rp 100 production costs that are incurred to provide income on farming suri cucumber Rp 90.19. Thus, farming cucumber suri in Gampong Babah Jurong Kuta Baro Aceh Besar District deserve to be organised and can give you an advantage..

Keywords: Farming, Income, Business

\section{PENDAHULUAN}

Timun suri merupakan tumbuhan semusim penghasil buah anggota suku labu-labuan (Cucurbitaceae). Timun suri memiliki bentuk lonjong dengan warna kulit kuning-hijau berpola garis-garis. Di balik bentuk dan warnanya, timun suri mengandung nutrisi seperti asam linoleat, glukosa, fluktosa, vitamin A, C, kalium, potasium, magnesium, dan saponin. Semua kandungan yang terdapat pada timun suri bagus dan baik bagi kesehatan serta kecantikan. Timun suri dapat berperan sebagai antioksidan bagi tubuh dengan menangkal radikal bebas sehingga tubuh tidak mudah terserang penyakit dan dapat mencegah penuaan dini. Dengan kandungan air dan serat, timun suri dapat membantu sistem pencernaan. 
Usahatani timun suri di Gampong Babah Jurong Kecamatan Kuta Baro Kabupaten Aceh Besar memanfaatkan lahan bantaran sungai sebagai lokasi penanaman timun suri. Terdapat 12 petani yang melakukan usahatani timun suri di Gampong Babah Jurong Kecamatan Kuta Baro Kabupaten Aceh Besar. Penanaman timun suri yang dilakukan petani bersifat musiman yang di pengaruhi oleh permintaan konsumen. Antusias konsumen untuk mengkonsumsi timun suri pada bulan puasa atau bulan ramadhan menjadi daya tarik bagi petani dalam melakukan usahatani timun suri. Dengan antusias permintaan konsumen terhadap timun suri maka mempengaruhi harga jual timun suri.

Harga jual timun suri pada bulan ramadhan di tingkat petani berkisar antara $\mathrm{Rp}$ $3.000 / \mathrm{kg}$ s.d $\mathrm{Rp}$ 4.000/kg . Fluktuasi harga jual timun suri tersebut mempengaruhi pendapatan yang terima oleh usahatani timun suri di Gampong Babah Jurong Kecamatan Kuta Baro Kabupaten Aceh Besar. Harga jual timun suri selain pada bulan ramadhan mengalami penurunan jika dibandingkan dengan harga jual timun suri pada bulan ramadhan. Harga jual timun suri di tingkat petani berkisar antara Rp 2.000/kg s.d Rp 3.000/kg, sedangkan harga jual timun suri di tingkat pedagang berkisar antara Rp 3.000/kg s.d Rp $4.000 / \mathrm{kg}$. Penurunan harga jual timun suri terjadi pada tingkat petani maupun tingkat pedagang. Hal tersebut dikarenakan permintaan terhadap timun suri sedikit.

Berdasarkan uraian harga penjualan dan jumlah produksi diatas maka tujuan dilaksanakan penelitian ini adalah untuk Menganalisis pendapatan usahatani timun suri di Gampong Babah Jurong Kecamatan Kuta Baro Kabupaten Aceh Besar dan Menganalisis kelayakan usahatani timun suri di Gampong Babah Jurong Kecamatan Kuta Baro Kabupaten Aceh Besar.

\section{Lokasi dan Waktu Penelitian}

\section{METODE PENELITIAN}

Penelitian ini dilakukan di Gampong Babah Jurong Kecamatan Kuta Baro Kabupaten Aceh Besar. Penelitian ini berlangsung pada bulan Mei sampai dengan bulan Juni tahun 2017

\section{Objek dan Ruang Lingkup Penelitian}

Objek penelitian adalah usahatani timun suri. Ruang lingkup penelitian terbatas pada variabel-variabel yang mempengaruhi pendapatan petani timun suri yang diantaranya produksi, luas lahan, harga jual, tenaga kerja, dan biaya.

\section{Sumber dan Metode Pengumpulan Data}

Data yang diperoleh selama proses penelitian melalui proses wawancara, observasi dan kuisioner. Data yang diperolah akan ditabulasi (data disajikan dalam bentuk tabel) agar lebih mudah dipahami. Instrumen penelitian yang digunakan untuk membantu proses penelitian adalah kuisioner terbuka.

\section{Model Analisis}

Metode ini digunakan untuk menganalisis pendapatan dan kelayakan usahatani timun suri di Gampong Babah Jurong Kecamatan Kuta Baro Kabupaten Aceh Besar. Data yang diperoleh dianalisis dengan analisis pendapatan (Dumairy, 2004), yakni dengan persamaan : $\mathrm{TC}=\mathrm{FC}+\mathrm{VC}$. Total revenue (total penerimaan) dapat di hitung dengan menggunakan rumus : $\mathrm{TR}=\mathrm{P} \times \mathrm{Q}$. Untuk mengetahui pendapatan pada usahatani suri dilakukan dengan rumus sebagai berikut $: \pi=\mathrm{TR}-\mathrm{TC}$ 


\section{a. Revenue Cost Ratio (R/C)}

$\mathrm{R} / \mathrm{C}$ merupakan perbandingan antara nilai penerimaan (TR) dengan total biaya produksi (TC). Untuk menghitung $\mathrm{R} / \mathrm{C}$ dengan menggunakan rumus :

$\mathrm{R} / \mathrm{C}=\frac{T R}{T C}$

(Soekartawi, 1995)

Kriteria Keputusan :

Jika $\mathrm{R} / \mathrm{C}>1$, maka usahatani timun suri menguntungkan.

Jika $\mathrm{R} / \mathrm{C}<1$, maka usahatani timun suri tidak menguntungkan atau rugi.

Jika $\mathrm{R} / \mathrm{C}=1$, maka usahatani timun suri berada pada keadaan titik pulang pokok

(untung/tidak rugi).

\section{b. Break Event Point (BEP)}

Break event point (BEP) merupakan keadaan yang menggambarkan suatu usahatani yang tidak memperoleh laba dan juga tidak mengalami kerugian. Usahatani akan mencapai keadaan BEP apabila total penerimaan sama dengan total biaya.

- BEP Produksi

$$
B E P=\frac{\text { Total Biaya Produksi }}{\text { Harga Jual Produk }}
$$

(Soekartawi, 1995)

- BEP harga

$$
B E P=\frac{\text { Total Biaya Produksi }}{\text { Total Produksi }}
$$

(Soekartawi, 1995)

\section{c. Return On Investment (ROI)}

Return On Investment (ROI) merupakan kemampuan suatu usaha untuk menghasilkan keuntungan yang akan digunakan untuk menutupi investasi yang dikeluarkan (Sutrisno, 2001).

$R O I=\frac{\text { Penerimaan-Biaya Produksi }}{\text { Biaya Produksi }} \times 100 \%$

(Sutrisno, 2001)

\section{HASIL PENELITIAN DAN PEMBAHASAN}

\section{Karakteristik Petani Responden}

Karakteristik petani responden usahatani timun suri dalam penelitian ini meliputi umur, pendidikan, pengalaman berusaha tani, jumlah tanggungan keluarga dan luas lahan. Rata-rata umur petani responden yaitu 44 tahun. Pada umumnya, umur berkaitan erat dengan kemampuan bekerja petani responden. Hal ini menunjukan bahwa umur petani responden berada pada katagori umur produktif. Umur yang masih tergolong produktif akan lebih memudahkan petani responden dalam bekerja secara optimal sehingga akan mempengaruhi pendapatan petani responden.

Pada rata-rata pendidikan petani responden di Gampong Babah Jurong Kecamatan Kuta Baro Kabupaten Aceh Besar adalah 12 tahun atau pada tingkat Sekolah Menengah Atas (SMA). Jika tingkat pendidikan petani responden rendah, maka akan memperlambat petani responden dalam mengadopsi inovasi dan mempertahankan kebiasaan-kebiasaan lama. Namun sebaliknya, jika tingkat pendidikan petani responden tinggi, maka akan lebih cepat petani responden dalam mengadopsi inovasi baru.

Lamanya pengalaman dalam usahatani dapat menjadikan petani responden lebih baik dalam mengelola usahataninya sehingga produksi dan pendapatan yang diterima dapat jauh lebih besar. Rata-rata pengalaman berusahatani di lokasi penelitian adalah 9 tahun. Hal ini 
menunjukkan petani responden sangat berpengalaman dalam usahatani timun suri. Petani responden yang lebih berpengalaman akan lebih matang dalam mengambil keputusan.

Rata-rata jumlah tanggungan keluarga petani responden adalah sebanyak 5 jiwa. Jumlah tanggungan keluarga akan mempengaruhi pengeluaran dan pendapatan petani responden, karena semakin banyak jumlah tanggungan maka akan semakin banyak pengeluaran dari segi konsumsinya.

Rata-rata luas lahan petani responden usahatani timun suri di Gampong Babah Jurong Kecamatan Kuta Baro Kabupaten Aceh Besar adalah $750 \mathrm{~m}^{2}$. Hal ini menunjukan bahwa petani responden di lokasi penelitian memiliki luas lahan yang cukup luas. Lahan yang dimiliki oleh petani responden di lokasi penelitian adalah lahan yang diberikan izin pakai oleh Pemerintah tanpa pajak, dan petani mengakui lahan tersebut sebagai milik pribadi sehingga pendapatan yang diterima oleh petani lebih besar.

\section{Analisis Pendapatan Usahatani Timun Suri}

Biaya produksi adalah biaya yang dikeluarkan selama proses produksi berlangsung, baik biaya tetap, seperti cangkul, sabit, parang, garu, hand sprayer, gerobak sorong, pompa air, dan selang air. Biaya variabel meliputi, benih timun suri, pupuk urea, pupuk NPK, pupuk ZA, zat pengatur tumbuh organik, pestisida organik, hand tractor, listrik, pelepah pisang, dan tali. Total biaya penyusutan adalah Rp 85.439/MT. Total biaya sarana produksi untuk lahan $750 \mathrm{~m}^{2}$ adalah sebesar Rp 818.717 /MT dan untuk lahan $1 \mathrm{Ha}$ Rp 10.916.222/MT. Total biaya penggunaan tenaga kerja untuk luas lahan $750 \mathrm{~m}^{2}$ adalah sebesar $\mathrm{Rp}$ 888.571/HKP/MT dan untuk luas lahan $1 \mathrm{Ha}$ adalah Rp

11.847.619/HKP/MT. Total biaya produksi yang dikeluarkan oleh usahatani di Gampong Babah Jurong Kecamatan Kuta Baro Kabupaten Aceh Besar untuk lahan dengan luas 750 m² $^{2}$ adalah sebesar Rp 1.792.727 /MT. Sedangkan untuk luas lahan 1 Ha membutuhkan biaya produksi sebesar Rp 23.903.023 /MT.

\section{Produksi, Harga Jual Produk dan Penerimaan}

Produksi yang dimaksud dalam penelitian ini adalah barang (produk) dari proses produksi yang dihasilkan pada usahatani timun suri dalam satuan kilogram, sedangkan nilai produksi merupakan penerimaan kotor yang diperoleh dari hasil produksi per petani dikalikan dengan harga jual petani yang dinyatakan dalam satuan mata uang rupiah. Pada harga jual produk yang dimaksudkan dalam penelitian ini, yaitu harga yang berlaku pada saat penelitian ini dilakukan.

Harga jual timun suri dari petani kepada pedagang di Gampong Babah Jurong Kecamatan Kuta Baro Kabupaten Aceh Besar berkisar antara Rp 3.000/kg s.d Rp 4.000/kg. Harga yang berlaku di tingkat petani adalah harga yang telah di sepakati oleh seluruh usahatani timun suri di Gampong Babah Jurong Kecamatan Kuta Baro Kabupaten Aceh Besar pada tahun 2017. Berikut ini adalah rata-rata produksi, rata-rata harga jual produk, dan penerimaan pada usahatani timun suri yang dapat dilihat pada Tabel berikut : 
Tabel 1. Produksi, Harga Jual Produk dan Penerimaan pada Usahatani Timun Suri di Gampong Babah Jurong Kecamatan Kuta Baro Kabupaten Aceh Besar, Tahun 2017

\begin{tabular}{cccr}
\hline No & \multicolumn{1}{c}{ Uraian } & Satuan & \multicolumn{2}{c}{$\begin{array}{c}\text { Total Biaya } \\
(\text { Rp/MT) }\end{array}$} \\
\hline 1. & Produksi & $\mathrm{Kg}$ & 861 \\
2. & Harga Jual Produk & $\mathrm{Rp} / \mathrm{Kg}$ & 3.567 \\
\hline Penerimaan/ 750 $\mathbf{~ m}^{\mathbf{2}}$ & & $\mathbf{3 . 1 6 6 . 7 2 5}$ \\
\hline Penerimaan/Ha & & $\mathbf{4 2 . 2 2 3 . 0 0 0}$ \\
\hline
\end{tabular}

Sumber : Data Primer (diolah), 2017

Tabel diatas menunjukkan bahwa penerimaan pada usahatani timun suri di Gampong Babah Jurong Kecamatan Kuta Baro Kabupaten Aceh Besar adalah Rp 3.166.725/MT dengan luas lahan sebesar $750 \mathrm{~m}^{2}$. Sedangkan untuk luas lahan $1 \mathrm{Ha}$ penerimaan yang didapatkan sebesar Rp 42.223.000/MT.

Harga jual timun suri selain pada bulan ramadhan (Mei-Juni) tahun 2017 pada tingkat petani berkisar antara $\mathrm{Rp} 2.000 / \mathrm{kg}$ s.d Rp $3.000 / \mathrm{kg}$ dan pada tingkat pedagang berkisar


kurangnya minat konsumen untuk mengkonsumsi timun suri di luar bulan ramadhan. Hal tersebut menjadi salah satu alasan mengapa petani responden di Gampong Babah Jurong Kecamatan Kuta Baro Kabupaten Aceh Besar tidak melakukan usahatani timun suri di luar bulan ramadhan (Mei-Juni tahun 2017). Namun demikian, timun suri masih bisa dijumpai pada toko buah atau pasar, tetapi sulit.

\section{Pendapatan dan Kelayakan Usahatani}

Untuk mengetahui besarnya pendapatan yang diperoleh petani responden pada usahatani timun suri di Gampong Babah Jurong Kecamatan Kuta Baro Kabupaten Aceh Besar, ada beberapa perhitungan yang harus dilakukan. Berikut tabel Rata-rata Pendapatan pada Usahatani Timun Suri di Gampong Babah Jurong Kecamatan Kuta Baro Kabupaten Aceh Besar, Tahun 2017.

Tabel 2. Rata-rata Pendapatan pada Usahatani Timun Suri di Gampong Babah Jurong Kecamatan Kuta Baro Kabupaten Aceh Besar, Tahun 2017

\begin{tabular}{|c|c|c|}
\hline No & Uraian & $\begin{array}{c}\text { Total Biaya } \\
\text { (Rp/MT) }\end{array}$ \\
\hline 1. & Total Penerimaan & 3.166 .725 \\
\hline \multirow[t]{3}{*}{2.} & Total Biaya Produksi & 1.792 .727 \\
\hline & Pendapatan/ $750 \mathrm{~m}^{2}$ & 1.373 .998 \\
\hline & Pendapatan/Ha & 18.319.977 \\
\hline
\end{tabular}

Sumber : Data Primer (diolah), 2017

Tabel diatas menunjukkan bahwa pendapatan yang diterima oleh usahatani timun suri di Gampong Babah Jurong Kecamatan Kuta Baro Kabupaten Aceh Besar adalah Rp 1.373.998 /MT dengan luas lahan sebesar $750 \mathrm{~m}^{2}$. Sedangkan untuk luas lahan $1 \mathrm{Ha}$ petani menerima pendapatan sebesar Rp 18.319.977 /MT. Dapat diketahui bahwa semakin besar penerimaan yang di dapatkan maka semakin besar pula pendapatan yang akan dihasilkan. 


\section{A. Revenue Cost Ratio $(R / C)$}

Berdasarkan hasil penelitian pada usahatani timun suri di Gampong Babah Jurong Kecamatan Kuta Baro Kabupaten Aceh Besar didapati nilai Revenue Cost Ratio $(R / C)$ pada Tabel berikut ini.

Tabel 3. Nilai R/C pada usahatani Timun Suri di Gampong Babah Jurong Kecamatan Kuta Baro Kabupaten Aceh Besar, Tahun 2017

\begin{tabular}{|c|c|c|}
\hline No & Uraian & $\begin{array}{c}\text { Total Biaya } \\
\text { (Rp/MT) }\end{array}$ \\
\hline 1. & Total Penerimaan & 3.166 .725 \\
\hline 2. & Total Biaya Produksi & 1.792 .727 \\
\hline & Pendapatan $/ 750 \mathrm{~m}^{2}$ & 1,77 \\
\hline
\end{tabular}

Sumber : Data Primer (diolah), 2017

Berdasarkan tabel diatas menujukkan bahwa nilai R/C $>1$ yaitu 1,77 yang artinya untuk setiap pengeluaran biaya satu rupiah dalam produksi timun suri akan memperoleh penerimaan sebesar Rp 177. Dengan demikian dapat disimpulkan bahwa usahatani timun suri di Gampong Babah Jurong Kecamatan Kuta Baro Kabupaten Aceh Besar layak untuk diusahakan dan dapat memberikan keuntungan.

\section{B. Break Event Point (BEP)}

Berdasarkan hasil penelitian pada usahatani timun suri di Gampong Babah Jurong Kecamatan Kuta Baro Kabupaten Aceh Besar didapati nilai Break Event Point (BEP) produksi dan Break Event Point (BEP) harga yang dapat di lihat pada Tabel berikut ini.

Tabel 4 . Nilai Break Event Point (BEP) pada Usahatani Timun Suri di Gampong Babah Jurong Kecamatan Kuta Baro Kabupaten Aceh Besar, Tahun 2017

\begin{tabular}{clr}
\hline No & \multicolumn{1}{c}{ Uraian } & Break Event Point $($ BEP) \\
\hline 1. & BEP Produksi $(\mathrm{Kg})$ & 503 \\
2. & BEP Harga $(\mathrm{Rp} / \mathrm{Kg})$ & 2.081 \\
\hline Sumber $:$ Data Primer (diolah), 2017 &
\end{tabular}

Berdasarkan Tabel diatas menunjukkan bahwa BEP produksi pada usahatani timun suri sebesar $503 \mathrm{~kg}$, artinya titik pulang pokok usahatani timun suri terjadi pada saat produksi $503 \mathrm{~kg}$, sedangkan BEP harga timun suri adalah Rp 2.081/kg, artinya titik pulang pokok usahatani timun suri dicapai pada harga minimun Rp 2.081/kg. Sedangkan BEP produksi pada usahatani timun suri dengan luas lahan $1 \mathrm{Ha}$ adalah sebesar $6.702 \mathrm{~kg}$, artinya titik pulang pokok usahatani timun suri terjadi pada saat produksi mencapai $6.702 \mathrm{~kg}$. BEP harga timun suri adalah $\mathrm{Rp} 2.081 / \mathrm{kg}$, artinya titik pulang pokok usahatani timun suri dicapai pada harga minimum Rp 2.081/kg.

\section{Return On Investment (ROI)}

Berdasarkan hasil penelitian pada usahatani timun suri di Gampong Babah Jurong Kecamatan Kuta Baro Kabupaten Aceh Besar didapati nilai Return On Investment (ROI) pada Tabel berikut ini. 
Tabel 5. Nilai Return On Investment (ROI) pada Usahatani Timun Suri di Gampong Babah Jurong Kecamatan Kuta Baro Kabupaten Aceh Besar, Tahun 2017

\begin{tabular}{clr}
\hline No & \multicolumn{1}{c}{ Uraian } & ROI \\
\hline 1. & Total Penerimaan & 3.166 .725 \\
2. & Total Biaya Produksi & 1.792 .727 \\
& ROI & $\mathbf{7 6 , 6 4 \%}$
\end{tabular}

Sumber : Data Primer (diolah), 2017

Berdasarkan Tabel diatas menunjukkan bahwa usaha tani timun suri di Gampong Babah Jurong Kecamatan Kuta Baro Kabupaten Aceh Besar memiliki nilai Return On Investment (ROI) sebesar 76,64 \%, artinya adalah setiap Rp 100 biaya produksi yang dikeluarkan mampu memberikan pendapatan pada usahatani timun suri sebesar Rp 76,64. Dengan demikian, hasil penelitian ini membuktikan bahwa usaha tani timun suri di Gampong Babah Jurong Kecamatan Kuta Baro Kabupaten Aceh Besar merupakan jenis usaha yang memiliki kemampuan memberikan pendapatan yang layak dari setiap biaya produksi yang dikeluarkan, khususnya pada usahatani timun suri.

\section{Kesimpulan}

\section{KESIMPULAN DAN SARAN}

Adapun kesimpulan dari penelitian ini adalah sebagai berikut:

a. Usahatani timun suri di Gampong Babah Jurong Kecamatan Kuta Baro Kabupaten Aceh Besar memberikan pendapatan bersih atau keuntungan sebesar Rp 1.373.998 /MT dengan luas lahan rata-rata $750 \mathrm{~m}^{2}$ dan Rp 18.319.977/MT untuk luas lahan 1 Ha.

b. Usahatani timun suri di Gampong Babah Jurong Kecamatan Kuta Baro Kabupaten Aceh Besar memiliki nilai Break Event Point (BEP) Produksi sebesar 503 kg, artinya titik pulang pokok usahatani timun suri terjadi pada saat produksi mencapai $503 \mathrm{~kg}$. Sedangkan Break Event Point (BEP) harga sebesar Rp 2.081/kg, artinya titik pulang pokok usahatani timun suri dicapai pada harga minimum Rp 2.081/kg. Nilai R/C sebesar 1,77 dimana jika R/C > 1 maka usahatani dinilai layak untuk diusahakan dan dapat memberikan keuntungan bagi pengelola usaha. Return On Investment (ROI) sebesar 76,64 \%, artinya adalah setiap Rp 100 biaya produksi yang dikeluarkan mampu memberikan pendapatan pada usahatani timun suri sebesar Rp 76,64. Dengan demikian, hasil penelitian ini membuktikan bahwa usaha tani timun suri di Gampong Babah Jurong Kecamatan Kuta Baro Kabupaten Aceh Besar merupakan jenis usaha yang memberikan pendapatan yang layak dari setiap biaya produksi yang dikeluarkan.

\section{Saran}

Berdasarkan hasil penelitian, maka dapat disarankan sebagai berikut :

a. Disarankan kepada petani untuk melanjutkan usahatani timun suri tersebut. Disamping perawatan yang mudah petani juga memperoleh pendapatan yang layak setiap musim panen. Dan untuk musim tanam berikutnya disarankan petani juga dapat menanam timun suri diluar dari bulan ramadhan (Mei-Juni) tahun 2017. 
b. Disarankan kepada pemerintah untuk mendukung usahatani timun suri dengan memberikan bibit unggul dan pupuk subsidi bagi usahatani timun suri.

\section{DAFTAR PUSTAKA}

Dodi, dkk. 2014. Analisis Pendapatan Usahatani Sayuran Di Kelompok Tani Jaya, Desa

Ciaruteun Ilir, Kecamatan Cibungbulang, Kabupaten Bogor. Jurnal Agribisnis.

Vol. 8, No.1, Juni 2014, Hlm 29-44.

Dumairy. 2004. Matematika Terapan Untuk Bisnis Dan Ekonomi. Edisi Keduabelas.

BPFE. Yogyakarta.

Gunawan, Ihksan. 2014. Analisis Pendapatan Usahatani Semangka (Citrullus Vulgaris) Di

Desa Rambah Muda Kecamatan Rambah Hilir Kabupaten Rokan Hulu. Program

Studi Agribisnis Universitas Pasir Pengaraian. Jurnal Sungkai. Vol. 2, No. 1, Edisi

Februari 2014, Hlm 52-63.

Gustiyana, H. 2004. Analisis Pendapatan Usahatani untuk Produk Pertanian. Salemba Empat.Jakarta.

Hernanto. 1994. Ilmu Usahatani. Penebar Swadaya. Jakarta.

Hidayat, muhammad Taufiq. 2013. Analisis Pendapatan Usahatani Mentimun Di Desa

Laladon, Kecamatan Ciomas, Kabupaten Bogor. Skripsi. Departemen Agribisnis

Fakultas Ekonomi dan Manajemen Institut Pertanian Bogor. Bogor.

Ridwan, dkk. 2014. Analisis Pendapatan Petani Kangkung Darat (Ipomea Reptans Poir)

Tradisional (Studi Kasus Desa Waru Kecamatan Mranggen Kabupaten Demak Jawa Tengah). Program Studi Agribisnis Fakultas Pertanian Universitas Wahid Hasyim. Jurnal Analisis Pendapatan. Vol. 10, No. 2, 2014, Hlm 81-89.

Soekartawi. 1995. Analisis Usahatani. UI-Press. Jakarta.

Sutrisno. 2001. Manajemen Keungan Teori, Konsep, dan Aplikasi. EKONISIA. Yogyakarta.

Yanti, Dely. 2014. Studi Kelayakan Usahatani Cabai Besar (Capsicum Annum L.) di Kelurahan Lampake Kecamatan Samarinda Utara. Agroteknologi, Fakultas Pertanian, Universitas 17 Agustus 1945 Samarinda. Jurnal AGRIFOR Vol. XIII No. 2, Oktober 2014, Hlm 149-154. 